\title{
Psychological Factors Influence the Symptoms of Gastroesophageal Reflux Disease: Author's Reply
}

TO THE EDITOR: We appreciate the interest and comments ${ }^{1}$ on our paper, ${ }^{2}$ which was published in the July 2012 issue of this Journal. The close correlation between gastroesophageal reflux disease (GERD) symptoms and psychological factors is well known, but this is the first study to show the relationship between typical GERD symptoms and psychological factors in patients with erosive esophagitis. ${ }^{3,4}$

You suggested in first point that the significant difference in the scores of somatization, obsessive-compulsive behavior and phobic anxiety might be rather statistically different because we did not investigate the scores of Symptom Checklist 90-Revision (SCL-90-R) in general population. We did not have a control group of general population in this study, but the SCL-90-R values of normal population are well established by previous studies. ${ }^{5,6}$ Although the absolute values of somatization, obsessivecompulsive behavior and phobic anxiety were relatively not high in the symptomatic erosive reflux disease group, the scores of the symptomatic group were higher than the scores of the asymptomatic group and the results were statistically significant. Nevertheless, if we had enrolled a control group of general population, we might have got a more accurate result.

In your second point, you indicated that it is unclear whether the psychological dimensions occur before the reflux symptoms and play an important role in the development of the GERD symptoms. We completely agree that it is important to clarify whether the psychological diseases are a consequence of the reflux symptoms or not. As you pointed out, it can be helpful to reanalyze the SCL-90-R data before and after proton pump inhibitor treatment. However, we will have many difficulties for interpretation of the results because of various internal and external factors such as patient compliance, proton pump inhibitor refractory cases and drug side effects.

\section{Sang Pyo Lee and Oh Young Lee \\ Department of Internal Medicine Hanyang University College of Medicine, Seoul, Korea}

1. Lee TH. Psychological factors influence the symptoms of gastroesophageal reflux disease. J Neurogastroenterol Motil 2012;18:460.

2. Lee SP, Lee KN, Lee OY, et al. The relationship between existence of typical symptoms and psychological factors in patients with erosive esophagitis. J Neurogastroenterol Motil 2012;18:284-290.

3. Núñez-Rodríguez MH, Miranda Sivelo A. Psychological factors in gastroesophageal reflux disease measured by scl-90-R questionnaire. Dig Dis Sci 2008;53:3071-3075.

4. Oh JH, Kim TS, Choi MG, et al. Relationship between psychological factors and quality of life in subtypes of gastroesophageal reflux disease. Gut Liver 2009;3:259-265.

5. Derogatis LR. SCL-90-R: Administration, scoring and procedures manual-II. Towson: Clinical Psychometric Research 1983.

6. Kim KI, Kim JH, Won HT. Korean manual of symptom checklist-90-revision. Seoul: Choong Ang Aptitude Publishing Co. 1984: 1-39.

\section{Conflicts of interest: None.}

